\title{
Translation and Validation of the Patient Activation Measure in Portuguese People with Type 2 Diabetes Mellitus
}

\section{Tradução e Validação do Questionário de Ativação do Doente (Patient Activation Measure) para Português, em Pessoas com Diabetes Mellitus Tipo 2}

\author{
Liliana LARANJO $\triangle^{1,2,3}$, Vera DIAS ${ }^{2}$, Carla NUNES ${ }^{2,3}$, Dagmara PAIVA ${ }^{4}$, Bill MAHONEY ${ }^{5}$ \\ Acta Med Port 2018 Jul-Aug;31(7-8):382-390 - https://doi.org/10.20344/amp.9072
}

\section{ABSTRACT}

Introduction: Management of diabetes mellitus is largely dependent on patients' active participation in care. The 'Patient Activation Measure 13' assesses patients' knowledge, skills, and confidence in self-care. We aimed to translate, culturally adapt, and validate the 'Patient Activation Measure 13' to Portuguese, in people with type 2 diabetes.

Material and Methods: The translation and cultural adaptation occurred in six phases. A convenience sample of people with type 2 diabetes was recruited from the waiting rooms of a diabetes outpatient centre in Lisbon, between March and April 2014. The questionnaire was self-administered; medical records were reviewed to obtain glycated haemoglobin levels. Main statistical analyses were based on the Rasch rating scale model.

Results: The response rate for the final questionnaire was $76 \%$. Rasch analysis was conducted on 193 respondents. Respondents had a mean age of 67.1 (SD 10.1) years, $42.7 \%$ were women, and the mean patient activation measure score $(0-100)$ in the sample was 58.5 (SD 10.1). The sample was low to moderate in terms of activation: $40.4 \%$ were low in activation (levels 1 and 2 ), $49.7 \%$ were in level 3 , and $9.8 \%$ were in level 4 , the highest level of activation. All items had good fit and the response categories functioned well. Item reliability was 0.97 and person reliability was between 0.77 (real) and 0.83 (model).

Discussion: The 'Patient Activation Measure 13' was translated and culturally adapted to European Portuguese and validated in people with diabetes, showing good psychometric properties. Future research should aim at evaluating test-retest reliability of the Portuguese 'Patient Activation Measure 13', and exploring its ability to measure changes in activation over time.

Conclusion: The 'Patient Activation Measure 13' is now available in European Portuguese and has good psychometric properties.

Keywords: Diabetes Mellitus, Type 2; Patient Participation; Patient Satisfaction; Portugal; Quality of Health Care; Self Care; Surveys and Questionnaires; Translations; Validation Studies

\section{RESUMO}

Introdução: A gestão da diabetes mellitus é, em grande parte, dependente da participação ativa dos doentes no processo de cuidados. O questionário de ativação do doente (Patient Activation Measure 13) avalia o conhecimento, capacidade técnica e confiança do doente nos auto-cuidados. Este estudo teve como objetivo a tradução, adaptação cultural e validação do questionário Patient Activation Measure 13 para português, em pessoas com diabetes tipo 2.

Material e Métodos: A tradução e adaptação cultural ocorreu em seis fases. O recrutamento decorreu nas salas de espera da Associação Protetora dos Diabéticos de Portugal, entre março e abril de 2014 (amostra de conveniência). O questionário foi autoadministrado; os valores de hemoglobina glicada foram obtidos a partir do processo clínico eletrónico. A análise psicométrica baseouse no modelo de Rasch.

Resultados: A taxa de resposta foi de 76\% e 193 indivíduos foram incluídos na análise psicométrica. A idade média dos participantes foi 67 (desvio padrão 10,1) anos, 42,7\% eram mulheres, e a média do score do Patient Activation Measure (0 - 100) na amostra foi 58,5 (desvio padrão 10,1). A amostra apresentou níveis baixos a moderados de ativação. Todos os itens apresentaram bom ajuste e as categorias de resposta funcionaram adequadamente. A fiabilidade dos itens foi 0,97 e a fiabilidade das pessoas encontrou-se entre 0,77 (real) e 0,83 (modelo)

Discussão: O Patient Activation Measure 13 foi traduzido e adaptado culturalmente para português, bem como validado em pessoas com diabetes mellitus tipo 2, revelando boas propriedades psicométricas. Estudos futuros deverão avaliar a fiabilidade teste-reteste do Patient Activation Measure 13 Português e explorar a capacidade do mesmo em avaliar alterações na ativação ao longo do tempo. Conclusão: O Patient Activation Measure 13 está agora disponível para utilização na população Portuguesa, apresentando boas propriedades psicométricas.

Palavras-chave: Autocuidado; Diabetes Mellitus Tipo 2; Estudos de Validação; Inquéritos e Questionários; Participação do Doente; Portugal; Qualidade de Cuidados de Saúde; Satisfação do Doente; Traduções

1. Australian Institute of Health Innovation - Centre for Health Informatics. Macquarie University. Sydney. Australia

2. Portuguese School of Public Health. Universidade Nova de Lisboa. Lisboa. Portugal.

3. Public Health Research Center (CISP/UNL). Lisboa. Portugal.

4. EPIUnit - Institute of Public Health. Universidade do Porto. Porto. Portugal.

5. Insignia Health. Portland. United States of America.

$\triangle$ Autor correspondente: Liliana Laranjo. liliana.laranjo@mq.edu.au

Recebido: 12 de abril de 2017 - Aceite: 14 de maio de 2018 | Copyright @ Ordem dos Médicos 2018 


\section{INTRODUCTION}

Patient-centred care is known to be associated with better health outcomes, efficiency, and satisfaction with care, particularly in patients with chronic diseases. ${ }^{1,2}$ Notably, one important element of the Chronic Care Model is the activated patient, with the skills, knowledge, and confidence to participate in care. ${ }^{1}$

The 13-item Patient Activation Measure (PAM13) is a patient-reported measure with strong psychometric properties that assesses a person's level of activation. ${ }^{3}$ Prior studies have shown that higher PAM13 scores are associated with better process and outcome measures. . $^{411}$

One disease where activation is known to be especially relevant is diabetes mellitus (DM). Activated patients with DM have been shown to be more likely to perform feet checks, to receive eye examinations, and to exercise regularly, as well as to have better metabolic control and report less difficulty in managing diabetes. ${ }^{2,12-15}$ On the contrary, DM patients with low levels of activation seem to have greater tendency to be hospitalized. ${ }^{16}$

Given the increasing prevalence and burden of type 2 DM, improving patient activation and promoting selfmanagement in this population seems crucial, in order to reduce the morbidity and mortality associated with the disease. ${ }^{17,18}$ However, empowering patients and engaging them in self-management remains a challenge, despite the recognition of its importance in the most recent guidelines. ${ }^{19}$

Two strategies are known to be effective in promoting self-management: tailoring and individualization of

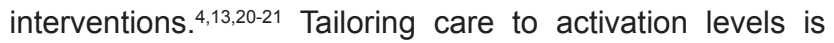
known to be associated with improvements in intermediate outcomes and greater reductions in hospitalizations and in emergency department use. ${ }^{4}$ Care may be tailored by encouraging small achievable steps for patients with low levels of activation, and supporting the adoption and maintenance of more difficult behaviours for those at higher levels of activation, therefore starting with goals that are appropriate for each patient's level of competency. ${ }^{7}$

The second strategy to promote self-management involves using the PAM in the consultation as part of a 'visual scan' approach, which consists of analysing a patient's responses to the questionnaire, identifying where there is less agreement with the statements, and then focusing on skill development, problem-solving and peer support in the areas of highest need (e.g. diet, physical activity), individualizing counselling and support. 3,5

The PAM13 was originally developed in the United States as an English questionnaire but it has already been translated and validated in several countries (e.g. Germany, Denmark, Netherlands, Israel, Spain) $)^{22-27}$ and applied to multiple patient populations (e.g. inflammatory bowel disease, mental health, chronic renal disease, heart failure, multimorbidity), ${ }^{28-32}$ which reflects its usefulness and importance.

The main objective of this study was to translate and culturally adapt the PAM13 to Portuguese, as well as to validate and test the psychometric properties of the Portuguese PAM13 (PAM13-P) in people with type 2 diabetes.

\section{MATERIAL AND METHODS \\ Participants and setting}

We followed a pre-defined protocol for the translation, cultural adaptation, and validation of the questionnaire, based on published recommendations. ${ }^{33}$

Participants were recruited from the waiting rooms of the Portuguese Diabetes Association's outpatient clinic (APDP-Diabetes), in Lisbon. The population of patients in APDP-Diabetes is heterogeneous - several patients receive all their diabetes-related care at this clinic, for lack of an available Family Physician/General Practitioner in their area of residence; others are referred to APDPDiabetes for management of their diabetes complications (e.g. retinopathy, diabetic foot).

Eligible patients for this study were diagnosed with type $2 \mathrm{DM}$, registered at APDP-Diabetes, fluent in Portuguese, and 18 years of age or older. Patients with dementia, blindness, deafness or inability to give informed consent were excluded.

1. When all is said and done, I am the person who is responsible for managing my health condition

2. Taking an active role in my own health care is the most important factor in determining my health and ability to function

3. I am confident that I can take actions that will help prevent or minimize some symptons or problems associated with my health condition

4. I know what each of my prescribed medications do

5. I am confident that I can tell when I need to go get medical care and when I can handle a health problem myself

6. I am confident I can tell my health care provider concerns I have even when he or she does not ask

7. I am confident that I can follow through on medical treatments I need to do at home

8. I understand the nature and causes of my health condition(s)

9. I know the different medical treatment options available for my health condition

10. I have been able to maintain the lifestyle changes for my health that I have made

11. I know how to prevent further problems with my health condition

12. I am confident I can figure out solutions when new situations or problems arise with my health condition

13. I am confident that I can maintain lifestyle chnages like diet and exercise even during times of stress

Figure 1 - Patient Activation Measure 13 (13-item questionnaire) 
Patients were recruited between March and April 2014 for cognitive debriefing sessions, pre-testing, and final questionnaire application. All participants gave written informed consent for participating in the study. No incentives were given to the participants. The Ethics Committee of APDP-Diabetes granted ethical approval of the study. Permission to translate the PAM13 to Portuguese and to conduct this study was granted from PAM13 developers and Insignia Health.

\section{Translation and cultural adaptation}

The process of translation and cultural adaptation of the original version of the PAM13 (Fig. 1) involved six phases ${ }^{33}$ (Fig. 2): 1) Forward-translation; 2) Back-translation; 3)
Harmonization; 4) e-Delphi; 5) Cognitive debriefing; 6) Appraisal and consensus.

Four independent bilingual translators carried out the forward translation and the back-translation stages, two of them in each of the stages (one with a medical background and one lay translator). During the harmonization stage, the translation and back-translation versions of the PAM were reconciled, focusing on cultural adaptation and readability.

An e-Delphi panel $(n=21)$ constituted by health researchers, health professionals (including family physicians), lay people, and DM patients, analysed the questionnaire in an iterative process. This phase was conducted via email, in several rounds, until consensus was reached. After each round, comments and suggestions

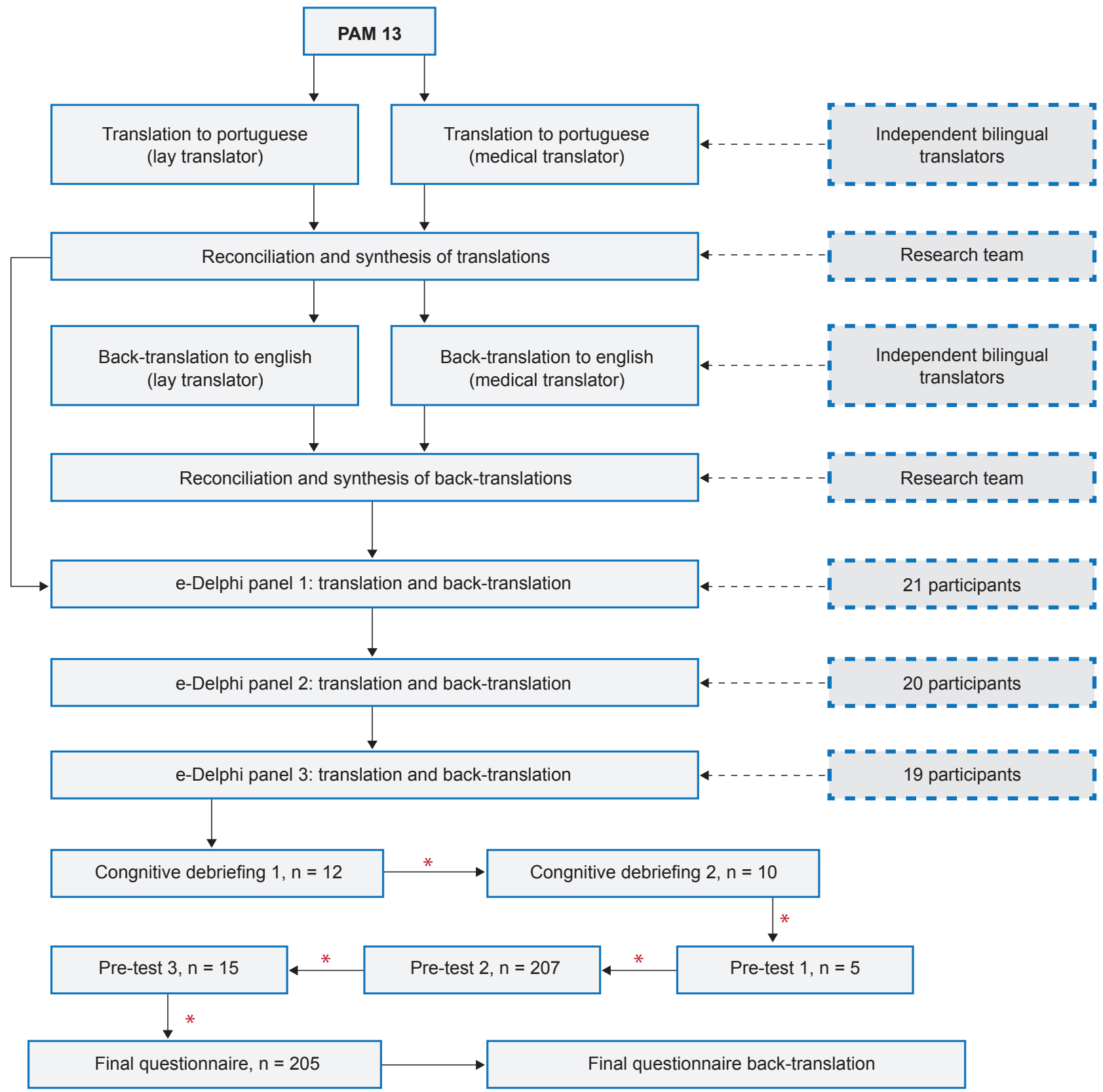

Figure 2 - Flow diagram of the translation, cultural adaptation and validation of the PAM13-P * review and modification by the research team 
were analysed, and the questionnaire was modified by the research team based on feedback. Equivalence between the source and pre-final versions was sought in five main areas: semantic, idiomatic, experiential, conceptual and cultural.

Two cognitive debriefing sessions were conducted to assess the general comprehension of the instrument by the target population. Each session was conducted with a convenience sample of people with type $2 \mathrm{DM}(\mathrm{n}=12$ and $\mathrm{n}$ =10), who were individually asked to complete the PAM13-P, think out loud, and discuss the meaning, interpretation, and phrasing of each item of the questionnaire.

Three rounds of pre-testing of the PAM13-P were conducted. The final questionnaire was applied in the waiting rooms of APDP-Diabetes during 6 working days in March and April 2014, as a self-administered paper questionnaire including the PAM13 and demographic and disease-specific questions (Appendix 1: https://www. actamedicaportuguesa.com/revista/index.php/amp/article/ view/9072/5483). We aimed at achieving a sample size greater than 150 participants for the final questionnaire, which is considered a large enough sample to allow for robust results using Rasch analysis. ${ }^{34}$

Demographic questions were used to assess age, gender, educational level and current occupation. Diseasespecific questions evaluated diabetes duration (in years) and current medication (none, oral antidiabetics and/or insulin). The most recent result of glycated hemoglobin (A1C) was collected from the electronic health record of each patient.

\section{Analysis and statistical methods}

Free-marginal multirater Kappa was used to evaluate agreement in the e-Delphi process. Response rates were calculated using the number of completed questionnaires in the numerator and the number of people invited to participate as the denominator. Pearson's correlation coefficient was used to assess correlation between continuous variables; chi-square tests were used to study associations between categorical variables, and ANOVA to test associations between categorical and continuous variables. Statistical analyses were performed using Statistical Package for the Social Sciences v21 ${ }^{\circledR}$, with alpha set at 0.05 .

Psychometric analysis of the PAM13-P was conducted with the Rasch rating scale measurement model via Winsteps v3.8.1 ${ }^{\circledR}$ (Rasch Measurement Software, Chicago, IL, USA). ${ }^{35}$ The analysis involved evaluating the fit of the data to the measurement model by examining the quality control fit statistics for response categories, items, and respondents. When the data fit the model the result is a true equal interval measurement scale of activation. The metric in Rasch analysis is the logit. Following the original PAM $13,{ }^{3}$ logits have been transformed into a more user friendly 0 to 100 scale, where 0 is the lowest possible score, and 100 is the highest (scoring instructions available from Insignia Health). This 0 - 100 score corresponds to a level of activation, varying from 1 (lowest activation) to 4 (highest level of activation), using previously defined cut-offs (level 1, $\leq 47$; level 2, 47.1 - 55.1; level 3, 55.2 - 67; level 4, $\geq$ 67.1). ${ }^{3}$

The reliability of item calibrations and generated activation scores of respondents was evaluated by item and person reliability coefficients. Rasch person reliability is the proportion of the total variability in measured activation that is not measurement error, and provides upper and lower bounds to the estimate of the 'true' reliability of the measure.

To test the comparability of the English and Portuguese version of the PAM item calibrations, a Mantel differential item functioning (DIF) analysis was performed in Winsteps. DIF analysis requires English and Portuguese items to be calibrated together, so that they share the same underlying scale. For the English language PAM, a simple random sample of 200 diabetes patients was selected from a larger sample of 1610 diabetes patients in a United States Health Maintenance Organization. Alpha for the Mantel chi-square was set at 0.01 .

Principal Components Analysis (PCA) of the standardized residuals was conducted to assess unidimensionality of the Portuguese items. ${ }^{34}$ The lower the eigenvalue of the standardized residuals (lower than 2.0) in the first contrast, i.e., the component that explains the largest possible amount of variance in the residuals, the more likely the residuals represent random noise and the instrument is unidimensional. If not, patterns of residuals (and not the loading values) were inspected to see if there were contrasts between opposing factors that could suggest multidimensionality. ${ }^{35}$

\section{RESULTS}

\section{Translation and cultural adaptation}

The two translations and back-translations were concordant on most items, except for minor differences in wording. For the reconciliation in a single translation, preference was given to less complex and semantically equivalent words and expressions.

The analysis of the harmonized translation and backtranslation of the PAM13 by the e-Delphi was done in three rounds (Fig. 2), until consensus was reached (round $1: \mathrm{n}=$ 21 , kappa $=0.63$; round $2: \mathrm{n}=20$, kappa $=0.80 ;$ round $3: \mathrm{n}$ =19, kappa $=0.96$ ).

\section{Characteristics of the study population}

The response rate for the final questionnaire was $76 \%$ (205 respondents). The 63 individuals who declined the invitation to participate were found to be similar to the respondents in terms of gender $(p>0.99)$ and age $(p=0.88)$. Four questionnaires were excluded before analysis: two individuals who were not able to complete the questionnaire due to poor vision, and two others that left the questionnaire blank after agreeing to participate.

Of the 201 respondents, eight had 'perfect scores', meaning that they had replied 'totally agree' to all 13 questions. It is customary in PAM research to delete these respondents since no data quality fit statistics can be 
Table 1 - Characteristics of the sample

\begin{tabular}{|c|c|c|c|c|c|}
\hline \multirow[b]{2}{*}{ Gender } & \multirow[b]{2}{*}{ Female } & \multirow[t]{2}{*}{$\begin{array}{c}\text { Mean (SD) } \\
\text { [Median (IQR)] }\end{array}$} & \multicolumn{2}{|c|}{$\mathrm{n}(\%)^{\mathrm{a}}$} & \multirow[t]{2}{*}{$\begin{array}{l}\text { PAM score } \\
{\text { (mean) })^{\mathrm{b}}}\end{array}$} \\
\hline & & & 82 & $(42.7)$ & \\
\hline $\begin{array}{l}\text { Age (years) } \\
\text { [Age range: } 36-91]\end{array}$ & & $\begin{array}{c}67.1(10.1) \\
{[67.0(13.0)]}\end{array}$ & & & \\
\hline \multirow[t]{4}{*}{ Schooling years } & $\leq 4$ & & 84 & $(43.5)$ & 58.6 \\
\hline & ]4; 9] & & 49 & $(25.3)$ & 57.9 \\
\hline & ]9; 12] & & 31 & $(16.1)$ & 55.9 \\
\hline & $>12$ & & 29 & $(15.0)$ & 61.6 \\
\hline \multirow[t]{3}{*}{ Occupation } & Retired & & 146 & $(75.6)$ & 59.2 \\
\hline & Employed & & 27 & $(14.0)$ & 56.1 \\
\hline & Unemployed & & 20 & $(10.4)$ & 56.3 \\
\hline \multirow[t]{3}{*}{ A1c $(\%)^{c}$} & & $\begin{array}{c}7.9(1.6) \\
{[7.7(1.9)]}\end{array}$ & & & \\
\hline & $<8$ & & 97 & $(58.4)$ & 59.6 \\
\hline & $\geq 8$ & & 69 & $(41.6)$ & 56.9 \\
\hline Diabetes duration (years) & & $\begin{array}{c}17.3(10.2) \\
{[16.0(13.0)]}\end{array}$ & \multicolumn{2}{|c|}{$193^{d}$} & \\
\hline Oral diabetes medication & Yes & & 150 & $(77.7)$ & \\
\hline Insulin use & Yes & & 115 & $(59.6)$ & \\
\hline
\end{tabular}

A1c: glycated haemoglobin; IQR: interquartile range; SD: standard deviation

a Sums may not add up to $100 \%$ due to rounding; ${ }^{b}$ Mean PAM scores are presented for relevant variables; ${ }^{\mathrm{c}} \mathrm{A} 1 \mathrm{c}$ results were from the last two years (approximately two thirds from the previous 3 months); ${ }^{d}$ Represents the total number of individuals for which there were valid data concerning each continuous variable.

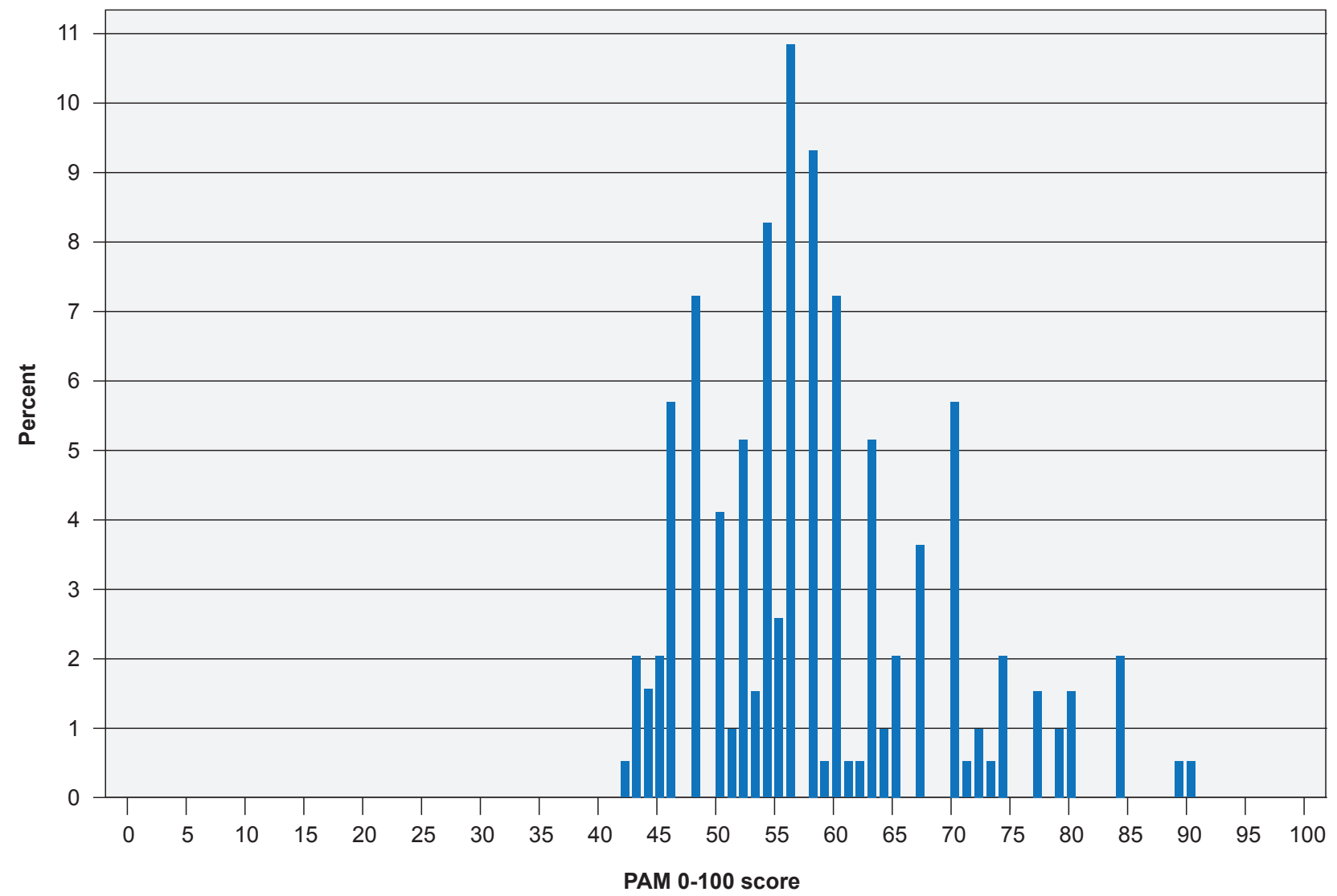

Figure 3 - Distribution of PAM scores in the sample of 193 patients with type 2 diabetes 
calculated when all answers are the same.

Rasch analysis was conducted on 193 respondents. Respondents had a mean age of 67 (SD 10.1) years, $42.7 \%$ were women, and the mean PAM score in the sample was 58.5 (SD 10.1) (Table 1). PAM scores varied from 41.8 to 90.5 (Fig. 3), reflecting no floor or ceiling effects. The sample was low to moderate in terms of activation: $40.4 \%$ were in levels 1 or $2,49.7 \%$ in level 3 , and the remaining in level 4 ( $\approx 9.8 \%)$.

Mean age differed significantly by PAM level: patients in level 4 were older (mean age 72 years) than those in level 1 (mean age 64; $F=2.75 ; p=0.044$ ). There was a trend towards lower $\mathrm{A} 1 \mathrm{c}$ values in patients with higher activation: mean $\mathrm{A} 1 \mathrm{C}$ in level 1 was $8.5 \%$ and in level 4 was $7.4 \%$ $(\mathrm{F}=1.59 ; p>0.05)$. There was no significant association between measured activation and gender, schooling, occupation, median diabetes duration or type of medication.

\section{Psychometric properties}

Item response was high, with missing answers varying between 0 and $7.8 \%$ (Table 2). The response categories had a good fit to the Rasch rating scale model (Table 3). Item reliability was 0.97 (both real and model), and person reliability was between 0.77 (real) and 0.83 (model).

All items had good fit to model expectations with item infit and outfit statistics ranging from 0.78 to 1.32 (Table 2). Item difficulty was smallest for item 4 (38.5), and highest for items 13 (56.1), 8 (55.4), and 10 (53.4).

DIF analysis comparing the English language and Portuguese versions of the PAM revealed four items with

Table 2 - Data quality, item difficulty, and fit statistics for the validation of the Portuguese PAM13

\begin{tabular}{|c|c|c|c|c|c|c|c|}
\hline Item & & $\begin{array}{l}\text { Total number } \\
\text { of responses }\end{array}$ & $\begin{array}{l}\text { Missing } \\
\text { values } \\
\mathrm{n}(\%)\end{array}$ & $\begin{array}{l}\text { 'Not applicable' } \\
\text { responses } \\
\mathrm{n}(\%)\end{array}$ & $\begin{array}{l}\text { Item } \\
\text { difficulty }\end{array}$ & Infit & Outfit \\
\hline 1. & $\begin{array}{l}\text { When all is said and done, I am } \\
\text { the person who is responsible for } \\
\text { managing my health condition }\end{array}$ & 193 & $0(0.0)$ & $0(0.0)$ & 43.6 & 1.12 & 1.17 \\
\hline 2. & $\begin{array}{l}\text { Taking an active role in my own health } \\
\text { care is the most important factor in } \\
\text { determining my health and ability to } \\
\text { function }\end{array}$ & 191 & $2(1.0)$ & $1(0.5)$ & 41.3 & 0.78 & 0.79 \\
\hline 3. & $\begin{array}{l}\text { I am confident that I can take actions } \\
\text { that will help prevent or minimize some } \\
\text { symptoms or problems associated with } \\
\text { my health condition }\end{array}$ & 180 & $13(6.7)$ & $9(4.7)$ & 42.9 & 0.87 & 0.84 \\
\hline 4. & $\begin{array}{l}\text { I know what each of my prescribed } \\
\text { medications do }\end{array}$ & 186 & 7 (3.6) & $5(2.6)$ & 38.5 & 0.96 & 0.93 \\
\hline 5. & $\begin{array}{l}\text { I am confident that I can tell when I } \\
\text { need to go get medical care and when } \\
\text { I can handle a health problem myself }\end{array}$ & 188 & $5(2.6)$ & $4(2.1)$ & 45.0 & 0.97 & 0.97 \\
\hline 6. & $\begin{array}{l}\text { I am confident I can tell my health care } \\
\text { provider concerns I have even when he } \\
\text { or she does not ask }\end{array}$ & 188 & $5(2.6)$ & $4(2.1)$ & 40.4 & 0.94 & 0.93 \\
\hline 7. & $\begin{array}{l}\text { I am confident that I can follow through } \\
\text { on medical treatments I need to do at } \\
\text { home }\end{array}$ & 193 & $0(0.0)$ & $0(0.0)$ & 41.0 & 0.87 & 0.82 \\
\hline 8. & $\begin{array}{l}\text { I understand the nature and causes of } \\
\text { my health condition(s) }\end{array}$ & 178 & $15(7.8)$ & $14(7.3)$ & 55.4 & 1.17 & 1.24 \\
\hline 9. & $\begin{array}{l}\text { I know the different medical treatment } \\
\text { options available for my health } \\
\text { condition }\end{array}$ & 179 & $14(7.3)$ & $13(6.7)$ & 51.4 & 0.95 & 0.98 \\
\hline 10. & $\begin{array}{l}\text { I have been able to maintain the } \\
\text { lifestyle changes for my health that I } \\
\text { have made. }\end{array}$ & 188 & $5(2.6)$ & $3(1.6)$ & 53.4 & 1.18 & 1.32 \\
\hline 11. & $\begin{array}{l}\text { I know how to prevent further problems } \\
\text { with my health condition }\end{array}$ & 184 & $9(4.7)$ & $7(3.6)$ & 50.9 & 1.00 & 1.04 \\
\hline 12. & $\begin{array}{l}\text { I am confident that I can figure out } \\
\text { solutions when new situations or } \\
\text { problems arise with my health condition }\end{array}$ & 181 & $12(6.2)$ & $12(6.2)$ & 50.3 & 0.98 & 1.00 \\
\hline 13. & $\begin{array}{l}\text { I am confident that I can maintain } \\
\text { lifestyle changes like diet and exercise } \\
\text { even during times of stress }\end{array}$ & 183 & $10(5.2)$ & $9(4.7)$ & 56.1 & 1.11 & 1.28 \\
\hline
\end{tabular}

Item difficulty is its location on the 0 - 100 activation scale (higher being more difficult); Infit and outfit: fit statistics assessing how well the items fit the model expectations; Infit is most sensitive when the person and item are close together on the scale; outfit is most sensitive when the item scale location is distant from the person scale location. 
Table 3 - Response category fit statistics

\begin{tabular}{lcccc}
\hline \multirow{2}{*}{ Response category } & \multicolumn{2}{c}{ Total times used } & Infit & Outfit \\
& $\mathrm{n}$ & $(\%)$ & & \\
\hline Disagree strongly & 40 & $(2)$ & 1.42 & 1.79 \\
Disagree & 321 & $(13)$ & 0.98 & 0.98 \\
Agree & 1495 & $(62)$ & 0.92 & 0.91 \\
Agree strongly & 556 & $(23)$ & 0.93 & 0.93 \\
\hline
\end{tabular}

Infit and outfit: fit statistics assessing item dimensionality. Infit is most sensitive when the person and item are close together on the scale; outfit is most sensitive to item dimensionality when the item scale location is distant from the person scale location.

significantly $(p \leq .01)$ different difficulty (Table 4$)$. Two items were significantly more difficult in English $(9,12)$ and two items were significantly more difficult in Portuguese $(2,7)$.

The Rasch dimension explained $39.1 \%$ of the variance in the data. Principal components analysis (PCA) of the standardized residuals revealed a first contrast with an eigenvalue of 2.29. The two items with the strongest positive loadings on the first contrast were items 10 and 13 , and the two items with the strongest negative loadings were items 6 and 7. Examination of the content of these four items shows that they do not appear to represent any meaningful continuum (e.g. physical - mental), since three of the four items address confidence and all four items concern behaviour. We conclude that there is no unexpected meaningful structure in items over and above that originally designed into the English PAM13.

\section{DISCUSSION}

\section{Main findings}

The PAM13 was successfully translated and culturally adapted to Portuguese, and validated in people with type $2 \mathrm{DM}$. To the best of our knowledge, this is the first study in Portugal measuring activation in patients with a chronic condition, and the first to validate the PAM13 in the Portuguese population. The final version of the PAM13-P was applied with a good response rate. Rasch analysis on 193 patients revealed good fit statistics, both for items and response categories, as well as good person reliability (between 0.77 and 0.83 ), and excellent item reliability (0.97).

\section{Strengths and limitations}

Our study incorporated many quality control steps in the process of translation and cultural adaptation, with a focus on achieving equivalence between the original PAM13 and the PAM13-P, in five major categories: semantic, idiomatic, experiential, conceptual and cultural. In order to make sure the PAM13-P was adapted to people with low reading levels, our e-Delphi process included lay people, and several cognitive debriefing sessions and pre-testing rounds were conducted. There was a good response rate and no age and gender differences were found between respondents and non-respondents, minimizing the impact of selection bias.

On the other hand, some caveats should be considered. Although our sample size was big enough to ensure the adequacy of the Rasch analysis and the validation process, our conclusions could have been strengthened by a larger and more diverse sample of the target population (e.g. with recruitment occurring in different hospitals and different geographic areas of the country). Potentially important variables could not be evaluated, namely socio-economic status, number of hospitalizations, hypoglycaemic and hyperglycaemic events, and emergency department admissions. Also, as frequently occurs in behavioural studies, our results were reliant on self-reports.

\section{Interpretation and comparison with existing literature}

Other validation studies of the PAM13 have been conducted, with comparable results, ${ }^{22-26}$ namely in people with type $2 \mathrm{DM}^{6}{ }^{6}$ There was a trend towards lower A1c

Table 4 - Differential item functioning (DIF) analysis comparing the English language and Portuguese version of the Patient Activation Measure 13

\begin{tabular}{lccccc}
\hline Item & Portuguese DIF calibration & English DIF calibration & Difference & Mantel chi-square & $p$-value \\
\hline 1. & 49.4 & 49.0 & 0.4 & 1.383 & 0.239 \\
2. & 48.0 & 40.7 & 7.3 & 11.509 & 0.001 \\
3. & 46.9 & 46.9 & 0.0 & 1.969 & 0.161 \\
4. & 44.5 & 47.6 & -3.1 & 0.200 & 0.655 \\
5. & 49.6 & 54.6 & 5.0 & 1.998 & 0.157 \\
6. & 46.4 & 46.8 & -0.4 & 0.165 & 0.684 \\
7. & 47.7 & 45.7 & 2.0 & 7.347 & 0.007 \\
8. & 54.7 & 49.1 & 5.6 & 0.272 & 0.602 \\
9. & 52.3 & 58.6 & -6.3 & 9.270 & 0.002 \\
10. & 55.8 & 50.4 & 5.4 & 5.932 & 0.015 \\
11. & 53.1 & 50.0 & 3.1 & 0.680 & 0.409 \\
12. & 51.9 & 59.3 & -7.4 & 16.039 & 0.000 \\
13. & 56.3 & 55.7 & 0.6 & 1.872 & 0.171 \\
\hline
\end{tabular}

DIF: differential item functioning

Item calibrations are shown in 0 - 100 units rather than logits for ease-of-understanding (conversion table available from Insignia Health Inc.) 
values in patients with higher activation, although this was not statistically significant. This association of activation with metabolic control has been previously described in the literature. ${ }^{36}$

All infit and outfit statistics for the 13 items were within the 0.5 - 1.5 acceptable range, and most were close to 1 , indicating an excellent fit of the items in the PAM13-P to the measurement model. ${ }^{37}$ Response categories had a good fit to the Rasch rating scale model, indicating that they work as intended in the PAM13-P. The 'disagree strongly' category was less frequently used, which is a common pattern seen in previous studies. ${ }^{3,22,25}$

As in other studies, item difficulty followed a slightly different order than observed in the original PAM13. ${ }^{22,25,26}$ Nevertheless, in general, there was a gradient of increasing difficulty from the first items to the last ones in the scale, reflecting the developmental model of activation suggested by the authors of the PAM. ${ }^{3,38}$ The 0 - 100 person measures varied from 38.5 to 53.4 , which is a range similar to the one found in the original PAM13 (38.6-53.0). ${ }^{3}$

The measurement had good person reliability, between 0.77 (real) and 0.83 (model), which is comparable with the original PAM13 (0.79- 0.83 in DM patients), ${ }^{3}$ and other PAM validations. $^{22}$ Item reliability was excellent (0.97), similarly to the original questionnaire. ${ }^{3}$

\section{Implications}

The validation of the PAM13-P is an important step in enhancing the use of patient-reported measures in primary care. The PAM13 is feasible to apply in the clinical setting, with minimal burden to patients and providers, ${ }^{3}$ being a rapid and reliable way of assessing activation levels, as well as identifying the areas of self-care where the patient is experiencing more difficulties. The PAM13 can be used both at the individual patient level, and at a group level, to guide and measure quality improvement efforts. ${ }^{4,20,39}$

Future research should aim at the refinement of the PAM13-P, evaluating test-retest reliability, and exploring its

\section{REFERENCES}

1. Bodenheimer T, Lorig K, Holman H, Grumbach K. Patient selfmanagement of chronic disease in primary care. JAMA. 2002;288:246975.

2. Parchman ML, Zeber JE, Palmer RF. Participatory decision making, patient activation, medication adherence, and intermediate clinical outcomes in type 2 diabetes: a starnet study. Ann Fam Med. 2010;8:4107.

3. Hibbard JH, Mahoney ER, Stockard J, Tusler M. Development and testing of a short form of the patient activation measure. Health Serv Res. 2005;40:1918-30.

4. Hibbard JH, Greene J, Tusler M. Improving the outcomes of disease management by tailoring care to the patient's level of activation. Am J Manag Care. 2009;15:353-60.

5. Greene J, Hibbard JH. Why does patient activation matter? An examination of the relationships between patient activation and healthrelated outcomes. J Gen Intern Med. 2012;27:520-6.

6. Rask KJ, Ziemer DC, Kohler SA, Hawley JN, Arinde FJ, Barnes CS. Patient activation is associated with healthy behaviors and ease in managing diabetes in an indigent population. Diabetes Educ. 2009;35:622-30.

7. Hibbard JH, Tusler M. Assessing activation stage and employing a "next ability to measure changes in activation over time, which could turn it into a useful tool to measure the effectiveness of patient-centred interventions.

\section{CONCLUSION}

The PAM13 is now translated and culturally adapted to European Portuguese, and has been validated in people with type 2 DM. The PAM13-P has good psychometric properties and should now be further tested in different settings and chronic disease populations.

\section{ACKNOWLEDGEMENTS}

The authors would like to thank Tiago Soares, Joaquim Ferreira, Armando Brito de Sá, and Osvaldo Santos for their insights during the design and implementation phases of this study; the translators and the e-Delphi participants for their valuable contribution; the study participants; and the Portuguese Diabetes Association (APDP-Diabetes) for enabling the successful implementation of this study.

\section{PROTECTION OF HUMANS AND ANIMALS}

The authors declare that the Ethics Committee of APDP-Diabetes granted ethical approval of the study and that the procedures followed the regulations established by the Helsinki Declaration of the World Medical Association.

\section{DATA CONFIDENTIALITY}

The authors declare having followed the protocols in use at their working center regarding patients' data publication.

\section{CONFLICTS OF INTEREST}

All authors report no conflict of interest.

\section{FUNDING SOURCES}

Liliana Laranjo was supported by a Junior Clinical Research award from the Harvard Medical School-Portugal program (HMSP-ICJ/0005/2010; Fundação para a Ciência e Tecnologia). steps" approach to supporting patient self-management. J Ambul Care Manage. 2007;30:2-8.

8. Aung E, Donald M, Coll JR, Williams GM, Doi SA. Association between patient activation and patient-assessed quality of care in type 2 diabetes: results of a longitudinal study. Health Expect. 2016;19:356-66.

9. Greene J, Hibbard JH, Sacks R, Overton V, Parrotta CD. When patient activation levels change, health outcomes and costs change, too. Health Aff. 2015;34:431-7.

10. Donald M, Ware RS, Ozolins IZ, Begum N, Crowther R, Bain C. The role of patient activation in frequent attendance at primary care: a population-based study of people with chronic disease. Patient Educ Couns. 2011;83:217-21.

11. Alegría M, Sribney $W$, Perez $D$, Laderman $M$, Keefe $K$. The role of patient activation on patient-provider communication and quality of care for US and foreign born Latino patients. J Gen Intern Med. 2009;24:S534-41.

12. Rost KM, Flavin KS, Cole K, McGill JB. Change in metabolic control and functional status after hospitalization. Impact of patient activation intervention in diabetic patients. Diabetes Care. 1991;14:881-9.

13. Bolen SD, Chandar A, Falck-Ytter C, Tyler C, Perzynski AT, Gertz AM, et al. Effectiveness and safety of patient activation interventions for adults with type 2 diabetes: systematic review, meta-analysis, and meta- 
regression. J Gen Intern Med. 2014;29:1166-76.

14. Williams GC, McGregor H, Zeldman A, Freedman ZR, Deci EL, Elder D. Promoting glycemic control through diabetes self-management: Evaluating a patient activation intervention. Patient Educ Couns. 2005;56:28-34.

15. Hendriks M, Rademakers J. Relationships between patient activation, disease-specific knowledge and health outcomes among people with diabetes; a survey study. BMC Health Serv Res. 2014;14:393.

16. Begum N, Donald M, Ozolins IZ, Dower J. Hospital admissions, emergency department utilisation and patient activation for selfmanagement among people with diabetes. Diabetes Res Clin Pract. 2011;93:260-7.

17. Tricco A, Ivers N, Grimshaw J, Moher D, Turner L, Galipeau J. Effectiveness of quality improvement strategies on the management of diabetes: a systematic review and meta-analysis. Lancet. 2012;379:2252-62.

18. Norris S, Engelgau M, Narayan K. Effectiveness of self-management training in type 2 diabetes: a systematic review of randomized controlled trials. Diabetes Care. 2001;24:561-87.

19. Laranjo L, Neves AL, Costa A, Ribeiro RT, Couto L, Sá AB. Facilitators, barriers and expectations in the self-management of type 2 diabetes - a qualitative study from Portugal. Eur J Gen Pract. 2015;21.

20. Hibbard JH, Mahoney ER, Stock R, Tusler M. Do increases in patient activation result in improved self-management behaviors? Health Serv Res. 2007;42:1443-63.

21. Gillani SM, Nevill A, Singh BM. Provision of structured diabetes information encourages activation amongst people with diabetes as measured by diabetes care process attainment: the WICKED Project. Diabet Med. 2015;32:865-71.

22. Maindal HT, Sokolowski I, Vedsted P. Translation, adaptation and validation of the American short form Patient Activation Measure (PAM13) in a Danish version. BMC Public Health. 2009;9:209.

23. Magnezi R, Glasser S. Psychometric properties of the Hebrew translation of the Patient Activation Measure (PAM-13). PLoS One. 2014;9:e113391.

24. Brenk-Franz K, Hibbard JH, Herrmann WJ, Freund T, Szecsenyi J, Djalali S, et al. Validation of the German version of the patient activation measure 13 (PAM13-D) in an international multicentre study of primary care patients. PLoS One. 2013;8:e74786.

25. Zill JM, Dwinger S, Kriston L, Rohenkohl A, Härter M, Dirmaier J. Psychometric evaluation of the German version of the patient activation measure (PAM13). BMC Public Health. 2013;13:1027.

26. Rademakers J, Nijman J, van der Hoek L, Heijmans M, Rijken M. Measuring patient activation in the Netherlands: translation and validation of the American short form Patient Activation Measure
(PAM13). BMC Public Health. 2012;12:577.

27. Moreno-Chico C, González-de Paz L, Monforte-Royo C, Arrighi E, Navarro-Rubio MD, Gallart Fernández-Puebla A. Adaptation to European Spanish and psychometric properties of the Patient Activation Measure 13 in patients with chronic diseases. Fam Pract. 2017;34:62734.

28. Munson GW, Wallston KA, Dittus RS, Speroff T, Roumie CL. Activation and perceived expectancies: correlations with health outcomes among veterans with inflammatory bowel disease. J Gen Intern Med. 2009;24:809-15.

29. Shively MJ, Gardetto NJ, Kodiath MF, Kelly A, Smith TL, Stepnowsky $\mathrm{C}$, et al. Effect of patient activation on self-management in patients with heart failure. J Cardiovasc Nurs. 2013;28:20-34.

30. Alegría M, Polo A, Gao S, Santana L. Evaluation of a patient activation and empowerment intervention in mental health care. Med Care. 2008;46:247-56.

31. Boyd CM, Wolff JL, Giovannetti E, Reider L, Weiss C, Xue Q-L, et al. Healthcare task difficulty among older adults with multimorbidity. Med Care. 2014;52:S118-25.

32. Bos-Touwen I, Schuurmans M, Monninkhof EM, Korpershoek Y, SpruitBentvelzen L, Ertugrul-van der Graaf I, et al. Patient and disease characteristics associated with activation for self-management in patients with diabetes, chronic obstructive pulmonary disease, chronic heart failure and chronic renal disease: a cross-sectional survey study. PLoS One. 2015;10:e0126400.

33. Wild D, Grove A, Martin M, Eremenco S, McElroy S, Verjee-Lorenz A, et al. Principles of good practice for the translation and cultural adaptation process for patient-reported outcomes (PRO) measures: report of the ISPOR Task Force for Translation and Cultural Adaptation. Value Health. 2005;8:94-104.

34. Linacre J. Sample size and item calibration stability. Rasch Meas Trans. $1994 ; 7: 328$

35. Linacre J. Winsteps ${ }^{\circledR}$ Rasch measurement computer program user's guide. Oregon: Beaverton; 2012.

36. Rogvi S, Tapager I, Almdal TP, Schiøtz ML, Willaing I. Patient factors and glycaemic control - associations and explanatory power. Diabet Med. 2012;29:e382-9.

37. Bond T, Fox C. Applying the Rasch model. Fundamental measurement in the human sciences. $2^{\text {nd }}$ ed. Mahwah: LEA; 2007.

38. Hibbard JH, Stockard J, Mahoney ER, Tusler M. Development of the Patient Activation Measure (PAM): conceptualizing and measuring activation in patients and consumers. Health Serv Res. 2004;39:100526.

39. Hibbard JH. Moving toward a more patient-centered health care delivery system. Health Aff. 2004;VAR133-5. 